\title{
Who's too old to screen? Prostate cancer in elderly men
}

\author{
Sandeep Mistry, MD; Wesley Mayer, MD; Rose Khavari, MD; Gustavo Ayala, MD; Brian Miles, MD
}

See related article on page 211

\section{Abstract}

Introduction: Prostate cancer is the most common nonskin malignancy affecting men and is the second leading cause of cancerrelated death in North America. The incidence of prostate cancer increases dramatically with age. However, many health authorities advocate the cessation of routine prostate cancer testing in men older than 75 because of the belief that most patients will have a clinically insignificant cancer and will not benefit from therapy. The true prevalence of clinically significant prostate cancer in elderly men is not known.

Methods: We analyzed 1446 needle biopsies of the prostate in men aged 75 or older. All pathological reviews were conducted by the pathology department at the Methodist Hospital in Houston, Tex. Data were collected from pathology reports, hospital and clinic databases, and medical records when available. Data obtained included age at biopsy, serum prostate-specific antigen (PSA) levels, number of positive core biopsies and Gleason grade. Statistical analysis was performed using Stata. Clinically significant cancer was defined by the pathological presence of Gleason grade 6 adenocarcinoma in more than 1 biopsy core or the presence of any Gleason 4 or 5 component in the biopsy. Results: The median age of the patients included in the study was 78.8 and $95 \%$ of the patients were between the ages of 75 and 85 . The mean serum PSA level for patients biopsied was $10.4 \mu \mathrm{g} / \mathrm{L}$. Of all biopsies reviewed, 53\% were positive for prostate cancer and $78 \%$ of these would be defined as clinically significant cancer. Regression analysis revealed age to be a significant $(p<0.05)$ factor for increased Gleason grade in positive biopsies. Logistic regression revealed age as a significant factor $(p<$ 0.05) for clinically significant prostate cancer even when controlling for PSA. A serum PSA threshold value of $6.5 \mu \mathrm{g} / \mathrm{L}$ would have missed $38 \%$ of significant cancers and a threshold of $4.0 \mu \mathrm{g} / \mathrm{L}$ would have missed $8 \%$ of significant cancers.

Conclusion: Our findings suggest that the prevalence of clinically significant prostate cancer in the elderly population may be higher than previously thought. As the population continues to live longer and healthier lives, it will become more common to confront prostate cancer morbidity in the eldery population. Using higher serum PSA thresholds to eliminate unnecessary biopsies in older men does not appear to help identify patients at greater risk of having clinically significant prostate cancer. Patients with prostate cancer having aggressive clinical features may benefit from treatment of their prostate cancer well into their eighth and ninth decades of life. Testing and diagnostic recommendations should reflect the potential benefit of identifying patients with aggressive prostate cancer even after age 75 .

Can Urol Assoc J 2009;3(3):205-10

\section{Résumé}

Introduction : Le cancer de la prostate est le type de cancer non cutané le plus fréquent chez les hommes et la seconde cause de décès lié au cancer en importance en Amérique du Nord. L'incidence du cancer de la prostate augmente grandement avec I'âge. Néanmoins, de nombreuses autorités en matière de santé avancent l'idée de mettre fin au dépistage systématique du cancer de la prostate chez les hommes de plus de 75 ans en raison de la croyance selon laquelle la plupart des patients présenteront un cancer non significatif sur le plan clinique et ne bénéficieront pas d'un traitement. La véritable prévalence des cas de cancer de la prostate cliniquement significatif chez les hommes âgés n'est pas établie.

Méthodes : Nous avons analysé 1446 échantillons de biopsie à I'aiguille prélevés au niveau de la prostate chez des patients de 75 ans ou plus. Toutes les analyses de pathologie ont été effectuées par le service de pathologie du Methodist Hospital de Houston, au Texas. Les données ont été tirées des rapports de pathologie, des bases de données des hôpitaux et des cliniques, et des dossiers médicaux lorsque possible. Les données obtenues incluaient l'âge au moment de la biopsie, les valeurs d'antigène prostatique spécifique (APS), le nombre de microbiopsies positives et le score de Gleason. Les analyses statistiques ont été effectuées à l'aide du système Stata. Le cancer cliniquement significatif est défini comme la présence d'un adénocarcinome avec un score de Gleason de 6 dans plus d'une zone de biopsie ou un score de Gleason de 4 ou 5 dans toute partie de l'échantillon.

Résultats : L'âge moyen des patients inclus était de 78,8 ans et $95 \%$ des patients avaient entre 75 et 85 ans. La valeur moyenne de l'APS chez les patients ayant subi une biopsie était de 10,4 $\mu \mathrm{g} / \mathrm{L}$. De tous les échantillons examinés, $53 \%$ confirmaient la présence d'un cancer de la prostate, et le cancer était défini comme étant cliniquement significatif dans $78 \%$ de ces cas. Une analyse de régression a révélé que l'âge était un facteur significatif ( $p<$ $0,05)$ lié à un score de Gleason plus élevé dans les biopsies positives. Une analyse de régression logistique a révélé que l'âge était aussi un facteur significatif $(p<0,05)$ lié à un cancer de la prostate 
cliniquement significatif même en tenant compte du taux d'APS. Une valeur seuil d'APS de 6,5 $\mu \mathrm{g} / \mathrm{L}$ serait passée à côté de $38 \%$ des cas de cancer significatif, alors qu'une valeur seuil d'APS de 4,0 $\mu \mathrm{g} / \mathrm{L}$ serait passée à côté de $8 \%$ des cancers significatifs. Conclusion : Nos observations portent à croire que la prévalence du cancer de la prostate significatif sur le plan clinique chez les patients âgés pourrait être plus élevée qu'on le croit. Avec I'augmentation de l'espérance de vie, l'incidence de la morbidité liée au cancer de la prostate augmentera. Le recours à des valeurs seuils d'APS plus élevées pour éliminer les cas de biopsies non nécessaires chez les hommes âgés ne semble pas aider à cerner les patients présentant un risque plus élevé de cancer de la prostate cliniquement significatif. Les patients atteints de cancer de la prostate cliniquement agressif peuvent bénéficier d'un traitement contre le cancer même lorsqu'ils dépassent largement les 80 ou les 90 ans. Les recommandations concernant le dépistage et le diagnostic devraient refléter les avantages potentiels liés au dépistage d'un cancer de la prostate agressif, même après 75 ans.

\section{Introduction}

Prostate cancer is the most common nonskin malignancy affecting men and is the second leading cause of cancerrelated death in North America. In 2007, there were an estimated 218890 new cases of prostate cancer and 27050 deaths, making prostate cancer the leading cause of cancer-related death in men. The incidence of prostate cancer increases dramatically with age. From 1998 to $2000,14.2 \%$ of men aged $65-79$ were diagnosed with prostate cancer compared with only $2.28 \%$ of men aged 40-59. ${ }^{1}$ Twenty-two percent of cancer mortality in men over the age of 80 is due to prostate cancer. ${ }^{1}$ As the proportion of our population over 75 increases, we can anticipate an increase in morbidity and mortality from prostate cancer.

The prostate cancer screening guidelines supported by the American Cancer Society and American Urologic Association recommend that all men older than 50 with an expected life expectancy of 10 years should undergo screening with serum prostate-specific antigen (PSA) testing and rectal examination. Many practitioners have adopted an age threshold of 70 or 75 to stop serum PSA testing and prostate biopsy because they believe that such men are not likely to live another 10 years. Furthermore, many urologists have adopted higher serum PSA thresholds or take a less aggressive stance toward biopsy and treatment of prostate cancer in older men. Some authors have even suggested that screening for prostate cancer is currently overused in elderly men. ${ }^{2}$ In August of 2008, the US Preventive Services Task Force recommendation statement was updated to read as follows:
Current evidence is insufficient to assess the balance of benefits and harms of screening for prostate cancer in men younger than age 75 years (I statement). Do not screen for prostate cancer in men age 75 years or older (Grade D recommendation). ${ }^{3}$

These recommendations were based on a review study on randomized, controlled trials and meta-analyses of PSA screening and cross-sectional and cohort studies concluding that PSA screening is associated with psychological harms, and that its potential benefits remain uncertain. ${ }^{4}$ Such a stance is predicated on the belief that most of these men will have prostate cancer of lower grade and stage with minimal clinical impact.

In an effort to test the hypothesis that men over the age of 75 should not be tested for prostate cancer because of an overabundance of indolent cancer, we examined the prostate biopsies of a large group of men in this age group.

\section{Methods}

We initially included in the study prostate needle biopsies of 1727 men aged 75 or older at the time of biopsy, performed at academic and nonacademic centres from December 1995 to June 2004 in the Houston, Tex., area. All biopsies were reviewed by the pathology department at Baylor College of Medicine in Houston. The patients had undergone biopsy because of either elevated serum PSA levels or abnormal results on digital rectal examination (DRE). The DRE findings were not available to the investigators for review. If a patient had more than 1 biopsy, only his most recent biopsy was included in the final analysis. Data were collected from pathology reports, hospital and clinic databases, and medical records. Information collected included age at biopsy, serum PSA level, number of core biopsies, number of positive core biopsies and Gleason grade. There were 1446 patients in the final analysis. In 272 patients, prostate volume was also available, allowing for calculation of PSA density.

Clinically significant cancer, as described in prior publications, was defined by the presence of a Gleason grade of 6 on more than 1 core, or the presence of any elements of Gleason grade 4 or $5 .{ }^{5}$ High-grade (poorly differentiated) cancer was defined by the presence of any elements of Gleason grade 4 or 5 in the biopsy specimen. Statistical analysis was carried out using Stata (Stata Corp.).

\section{Results}

The median age of the patients included in our analysis was 78 (range 75-99) years with 95\% of the patients between the ages of 75 and 85 (Fig. 1).

Of all biopsies reviewed, $53 \%$ were positive for prostate 
cancer and $78 \%$ of these would be defined as clinically significant cancer. As Figure 2 demonstrates, use of a serum PSA threshold of $6.5 \mu \mathrm{g} / \mathrm{L}$ for older patients, as some authors have suggested, ${ }^{6}$ would have missed $38 \%$ of significant cancer and $37 \%$ of high-grade cancer. Using a serum PSA threshold of $4.0 \mu \mathrm{g} / \mathrm{L}$ would have missed only $8 \%$ of significant cancers and $9 \%$ of high-grade cancer.

The mean serum PSA level for all patients in our sample population was $10.4 \mu \mathrm{g} / \mathrm{L}$. Patients with a negative biopsy had a mean serum PSA level of $7.7 \mu \mathrm{g} / \mathrm{L}$, and patients with a positive biopsy had a mean serum PSA level of $13.0 \mu \mathrm{g} / \mathrm{L}$. Patients with clinically significant cancer had a mean serum PSA level of $14.0 \mu \mathrm{g} / \mathrm{L}$ and those with a Gleason 4 or 5 component found in the biopsy had a mean serum PSA level of $15.5 \mu \mathrm{g} / \mathrm{L}$. Although mean serum PSA values tended to increase with more aggressive pathological features, the distribution of serum PSA values for patients with no cancer, clinically significant cancer or high-grade cancer were not statistically distinguishable (Fig. 3).

High-grade carcinoma, defined by a Gleason component of 4 or 5 on biopsy (Gleason grade 7 to 10), was found in $33 \%$ of our patients and accounted for $63 \%$ of cancers detected. When examining only patients with a serum PSA

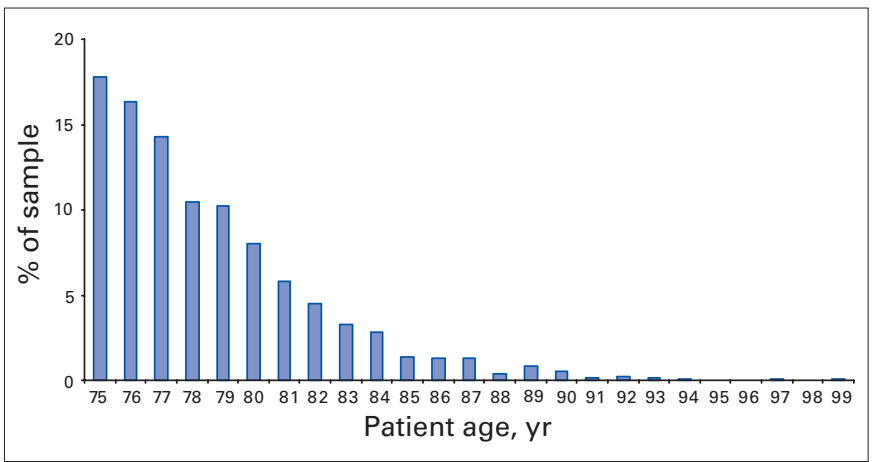

Fig. 1. Age distribution of patients included in the analysis.

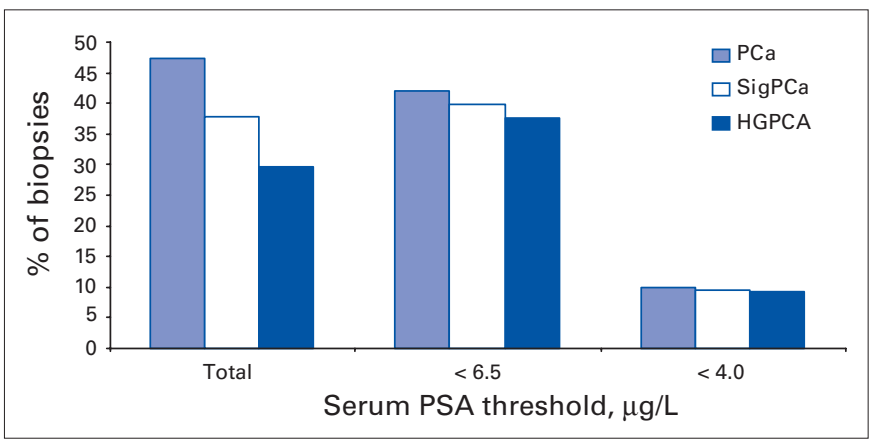

Fig. 2. Percentage of biopsies that were positive for prostate cancer. $\mathrm{PCa}=$ prostate adenocarcinoma; $\mathrm{PSA}=$ prostate-specific antigen; $\mathrm{Sig} \mathrm{PCa}=$ significant prostate adenocarcinoma; HGPCA = high-grade prostate adenocarcinoma. level between 4 and $10 \mu \mathrm{g} / \mathrm{L}$, we found that $59 \%$ of our patients had serum PSA values within this range. Of those with a serum PSA level between 4 and $10 \mu \mathrm{g} / \mathrm{L}, 30 \%$ of patients were found to have high-grade prostate cancer representing $56 \%$ of all cancer detected. For patients with serum PSA values greater than $10 \mu \mathrm{g} / \mathrm{L}, 79 \%$ of all cancers detected would be classified as high grade.

A receiver operating characteristic analysis determined a PSA density of 0.15 to be predictive of clinically significant prostate cancer with a sensitivity of $56.2 \%$ and specificity of $86.4 \%$ (Fig. 4 ).

Logistic regression analysis revealed each year over 75 , adjusted for PSA, to be a significant $(p<0.05)$ factor for increased Gleason grade found on biopsy. Serum PSA levels were not correlated with age in our sample's age range. Logistic regression revealed age as a significant factor $(p<0.05)$ for clinically significant prostate cancer even when correcting for PSA and prostate volume (Fig. 5).

\section{Discussion}

The aging population presents a challenge in regard to the testing, diagnosis and treatment of prostate cancer. It is widely believed that men aged 75 or older should not be routinely screened for prostate cancer. ${ }^{2-5} \mathrm{~A}$ national survey found that less than $58 \%$ of primary care physicians and less than $50 \%$ of urologists routinely perform PSA tests in healthy men over the age of 75. The decision of which patients to biopsy is largely left up to the treating urologist. Less than $13 \%$ of urologists surveyed felt that men over the age of 75 with a serum PSA level between 4 and $10 \mu \mathrm{g} / \mathrm{L}$ should undergo prostate biopsy.

Lin and colleagues, ${ }^{4}$ in a review study of randomized, controlled trials, meta-analyses of PSA screening, crosssectional and cohort studies of screening harms, and of the

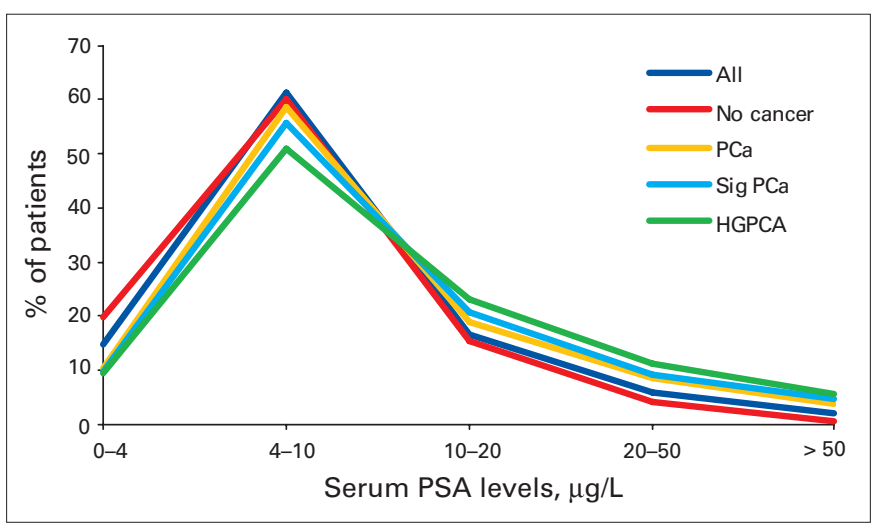

Fig. 3. Distribution of serum prostate-specific antigen (PSA) levels. $\mathrm{PCa}=$ prostate adenocarcinoma; $\mathrm{Sig} \mathrm{PCa}=$ significant prostate adenocarcinoma; HGPCA = high-grade prostate adenocarcinoma . 
natural history of screening-detected cancer, reported that no good-quality randomized, controlled trials of screening for prostate cancer have been completed. In addition they reported that in 1 cross-sectional and 2 prospective cohort studies of fair to good quality, false-positive PSA screening results caused adverse psychological effects for up to 1 year after the test. The authors concluded that PSA screening is associated with psychological harms and that its potential benefits remain uncertain. This conclusion led to an update of the US Preventive Services Task Force recommendations to not screen for prostate cancer in men aged 75 years or older (Grade D recommendation). ${ }^{3}$

The reason for the avoidance of screening and biopsy for prostate cancer in older patients is multifactorial. The ambiguous natural history of prostate cancer is at the heart of many differences in practice patterns among urologists. Some physicians hesitate to screen elderly men because they feel that mortality will be due to a competing cause. ${ }^{8} \mathrm{~A} 10$-year life expectancy has been an arbitrary basis for using 70 or 75 as the point to stop aggressive screening for prostate cancer. Recent retrospective studies have shown similar 10-year survival rates between watchful waiting and radical prostatectomy in patients with well to moderately differentiated prostate cancer (Gleason grade 2-6). However, men with poorly differentiated cancer can experience a survival advantage from treatment in as little as 5 years. ${ }^{9,10}$

In our series of 1446 patients, $79 \%$ of all cancers found at biopsy were found to be clinically significant. Furthermore, $63 \%$ of these men had an element of Gleason grade 4 or 5 compared with about $20 \%$ of prostate cancers defined as high-grade reported in patients under the age of $70 .{ }^{9}$ The fact that only $21 \%$ of patients in our study had what would be called clinically insignificant cancer reas-

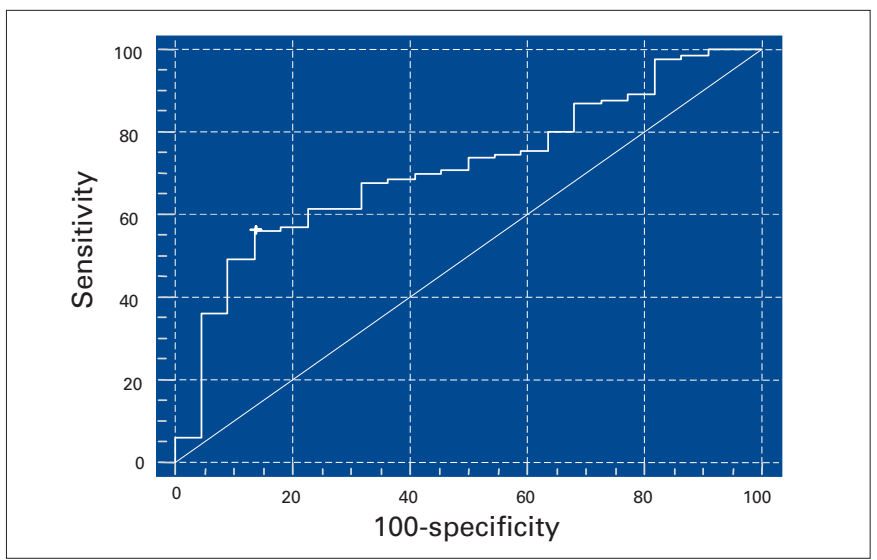

Fig. 4. Receiver operating characteristic curve showing a prostate-specific antigen density of 0.15 to be predictive of clinically significant prostate cancer with a sensitivity of $56.2 \%$ and specificity of $86.4 \%$. sures that we are not overtesting. We feel that these patients should be encouraged to undergo watchful waiting. Diagnosis with prostate cancer does not equate with need for invasive therapy and appropriate informed consent can obviate unnecessary treatment. However, many of the patients with clinically significant cancer could experience a survival advantage if treated early.

On average, the serum PSA levels were quite high in our study population. It could be argued that, given the higher mean serum PSA level in our sample population, these men were simply missed by screening efforts when they were younger or their referrals for biopsy were delayed. However, even when adjusting for serum PSA levels, our sample population demonstrated a statistically significant risk of developing high-grade disease for each year after 75 . The higher mean serum PSA value in our sample population may also illustrate a tendency of urologists to delay biopsy in older individuals with elevated serum PSA values. The risk of delayed biopsy is progression of disease to a more advanced state. Richardson and Oesterling ${ }^{6}$ established "age-specific" reference ranges for serum PSA levels. For men aged 70 to 79 , they suggested a normal serum PSA reference range of $0.0-6.5 \mathrm{ng} / \mathrm{mL}(0.0-6.5 \mu \mathrm{g} / \mathrm{L})$. In our population, $38 \%$ of patients with clinically significant and $37 \%$ with high-grade prostate cancer had a serum PSA level lower than $6.5 \mu \mathrm{g} / \mathrm{L}$ and would have been missed using agespecific guidelines. Although patients in our series with high-grade cancer had higher mean serum PSA values, serum PSA levels were a poor predictor of clinically significant prostate cancer. In fact, most of our patients had a serum PSA level between 4 and $10 \mu \mathrm{g} / \mathrm{L}$ and over half of the cancer detected contained a Gleason 4 or 5 component. Prostate-specific antigen density was not sensitive for clinically significant cancer but was relatively specific for selecting out patients unlikely to have clinically significant cancer. Our data suggests that use of higher serum PSA thresholds or the delay of prostate biopsy increases the

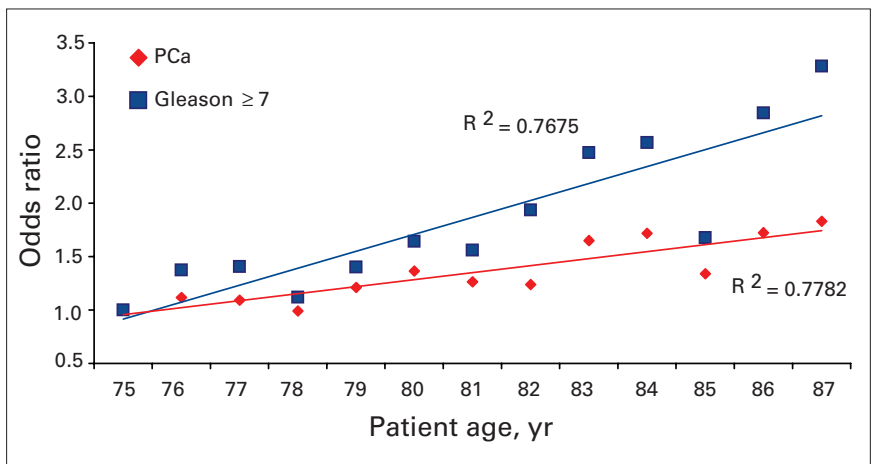

Fig. 5. Logistic regression revealed age as a significant factor $(p<0.05)$ for clinically significant prostate cancer. $\mathrm{PCa}=$ prostate adenocarcinoma. 
likelihood of missed high-grade tumours with a higher likelihood of progression.

Another criticism that could be brought to our study is that we did not include DRE findings, which were not available at the time of the study. Philip and colleagues, ${ }^{8}$ looking at the necessity of DRE in the diagnosis and clinical staging of prostate cancer, reported no correlation between the DRE, biopsy findings and pathological staging. Therefore the authors suggested that DRE does not contribute to the management of patients with prostate cancer when there is a serum PSA level of $2.5-10 \mathrm{ng} / \mathrm{mL}(2.5-10 \mu \mathrm{g} / \mathrm{L})$. This does not mean that there is no place for physical examination, especially DRE, but we were limited in the physical examination data available to us.

The routine performance of biopsies in men older than 75 who have elevated serum PSA values $(>4.0 \mu \mathrm{g} / \mathrm{L})$ raises difficult questions regarding treatment. Alibhai and colleagues ${ }^{11}$ used a decision-analytic Markov model to evaluate available treatments for localized prostate cancer in men aged 65 or older. They estimated life expectancy and quality-adjusted life expectancy associated with radical prostatectomy, external beam radiotherapy and watchful waiting. For poorly differentiated disease, potentially curative therapy resulted in life expenctancy and qualityadjusted life expectancy gains in patients diagnosed up to age 80 years. ${ }^{9}$

Chodak and colleagues ${ }^{10}$ performed a meta-analysis of 828 men with clinically localized prostate cancer who were treated conservatively (with watchful waiting or delayed hormone therapy). They found that mortality matched for Gleason grade was not affected by age and that watchful waiting is not appropriate for patients with poorly differentiated cancer. In our series, $29 \%$ of patients with cancer were found to have a Gleason grade of 8 or higher and $63 \%$ had high-grade prostate cancer (Gleason component of 4 or 5). This intermediate high-grade group (Gleason $3+4$ or $4+3$ ) was not well defined or evaluated in the study by Chodak and coauthors and may represent a population for whom early definitive therapy may be warranted.

Concerning the impact of competing comorbidities in the elderly age group, Sweat and colleagues ${ }^{12}$ retrospectively analyzed a cohort of 751 men, aged up to 74, with clinically nonmetastatic prostate cancer. After consideration of competing comorbidities, the estimated cumulative incidence of mortality from prostate cancer increased with Gleason grade regardless of patient age.

Tewari and colleagues ${ }^{13}$ used a propensity risk approach to model long-term survival for men with clinically localized prostate cancer based on a cohort of 1611 men with clinically localized prostate cancer and 4538 age-, raceand comorbidity-matched controls. They found a survival benefit with curative therapy (radiation or prostatectomy) over conservative treatment in older men, even those with severe comorbidities.

Men who are 75 years old today are not the 75 -year-olds of 50 years ago; they are physically younger, and still sexually active in many cases. Stangelberger and coauthors ${ }^{14}$ believe that in men older than 70 years, treatment without curative intent may deprive the frail patient of years of life, emphasizing that modern radical prostatectomy techniques with low perioperative morbidity, excellent clinical outcome and documented long-term disease control should be considered for local treatment of organ-confined prostate cancer potentially as a cure. The authors suggested that no age cut-off has been suggested for PSA testing and healthy elderly men should be checked routinely.

Because most published long-term watchful waiting protocols identify prostate cancer by fine needle aspiration and largely exclude poorly differentiated cancers, it is difficult to know if men over the age of 75 are well represented in these surveillance studies. Clearly, the impact of any highgrade disease in the "very elderly" must be assessed in follow-up outcome studies.

The retrospective and noncontrolled design of this study limits our ability to generalize the findings. Furthermore, complete information on prior serum PSA values, DRE findings, clinical history and indication for biopsy would have provided a more complete picture of current clinical management of these elderly men. Finally, we have no longterm follow-up data on these men to evaluate the impact of prostate cancer and its treatment on the quality and longevity of their lives.

\section{Conclusion}

Our findings suggest that the prevalence of clinically significant prostate cancer in the elderly population may be higher than previously thought. The use of higher serum PSA thresholds to eliminate unnecessary biopsies in older men does not appear to help identify patients at greater risk of having clinically significant prostate cancer. Testing and diagnostic recommendations should reflect the potential benefit of the identification of patients with aggressive prostate cancer even after age 75 . Urologists should not be encouraged to avoid biopsy of the prostate in the elderly simply because of concerns about "overdiagnosis and overtreatment" of clinically insignificant disease. Prostate cancer detection should not be the issue. Prostate cancer treatment is. The decision to treat elderly men with prostate cancer should be made based on a thorough assessment of life expectancy, patient preference and outcome expectations based on pathological criteria. Detection allows 
Mistry et al.

patients and their urologist to discuss treatment and management from a basis of knowledge, not avoidance. Given the high rate of mortality from prostate cancer in the elderly, and the aging trends in the United States, any credible effort to reduce prostate cancer morbidity and mortality will need to focus on the re-examination of attitudes toward the screening and treatment of elderly men for prostate cancer.

From the Scott Department of Urology, Baylor College of Medicine, Houston, Tex.

This article has been peer reviewed.

Competing interests: None declared.

\section{References}

1. American Cancer Society. Cancer facts \& figures 2003. Available: www.cancer.org/downloads /STT/CAFF2003PWSecured.pdf (accessed 2009 Apr 28).

2. Lu-Yao G, Stukel TA, Yao SL Prostate-specific antigen screening in elderly men. J Natl Cancer Inst 2003;95:1792-7.

3. U.S. Preventive Services Task Force. Screening for prostate cancer: U.S. Preventive Services Task Force recommendation statement. Ann Intern Med 2008;149:185-91.

4. Lin K, Lipsitz R, Miller T, et al. Benefits and harms of prostate-specific antigen screening for prostate cancer: an evidence update for the U.S. Preventive Services Task Force. Ann Intern Med 2008;149:192-9.
5. Noguchi M, Stamey TA, McNeal JE, et al. Relationship between systematic biopsies and histological features of 222 radical prostatectomy specimens: lack of prediction of tumor significance for men with nonpalpable prostate cancer. J Urol 2001;166:104-9.

6. Richardson TD, Oesterling JE. Age-specific reference ranges for serum prostate specific antigen. Urol Clin North Am 1997;24:339-51.

7. Fowler FJ Jr, Bin L, Collins MM, et al. Prostate cancer screening and beliefs about treatment efficacy: a national survey of primary care physicians and urologists. Am J Med 1998;104:526-32.

8. Philip J, Dutta Roy $S$, Ballal $M$, et al. Is a digital rectal examination necessary in the diagnosis and clinical staging of early prostate cancer? BJU Int 2005;95:969-71.

9. Lu-Yao G, Stukel TA, Yao SL. Changing patterns in competing causes of death in men with prostate cancer: a population based study. J Urol 2004;171:2285-90.

10. Chodak GW, Thisted RA, Gerber GS, et al. Results of conservative management of clinically localized prostate cancer. N Engl J Med 1994;330:242-8.

11. Alibhai $S M$, Naglie $G$, Nam R, et al. Do older men benefit from curative therapy of localized prostate cancer? J Clin Oncol 2003;21:3318-27.

12. Sweat SD, Bergstralh EJ, Slezak J, et al. Competing risk analysis after radical prostatectomy for clinically nonmetastatic prostate adenocarcinoma according to clinical Gleason score and patient age. J Urol 2002;168:525-9.

13. Tewari A, Johnson $\mathrm{CC}$, Divine $\mathrm{G}$, et al. Long-term survival probability in men with clinically localized prostate cancer: a case-control, propensity modeling study stratified by race, age, treatment and comorbidities. J Urol 2004;171:1513-9.

14. Stangelberger A, Waldert M, Djavan B. Prostate cancer in elderly men. Rev Urol 2008;10:111-9.

Correspondence: Dr. Brian Miles, Scott Department of Urology, Baylor College of Medicine, 6624 Fannin St., Suite 2280, Houston TX 77030; bmiles@drbrianmiles.com

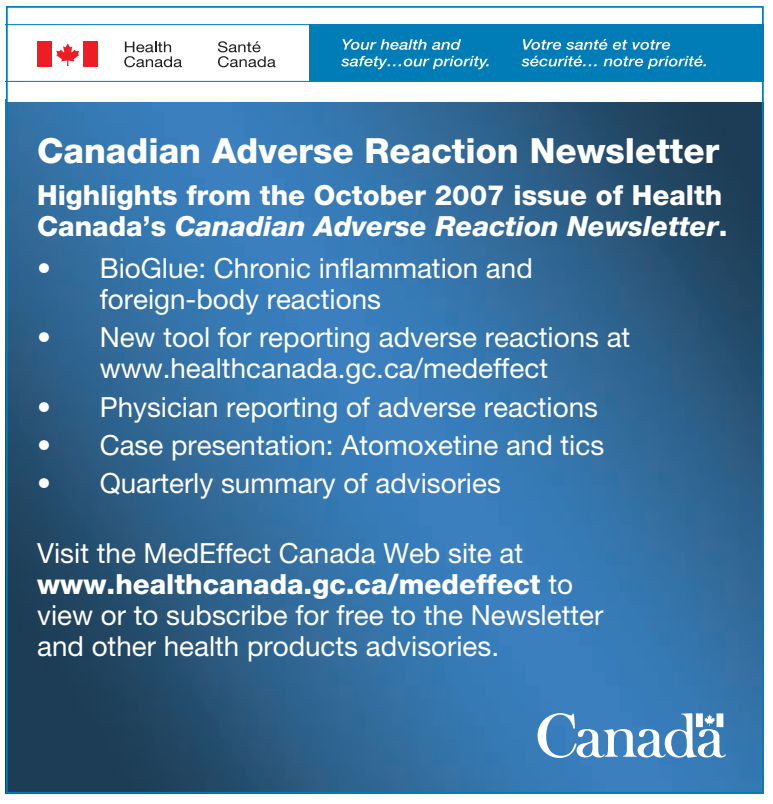

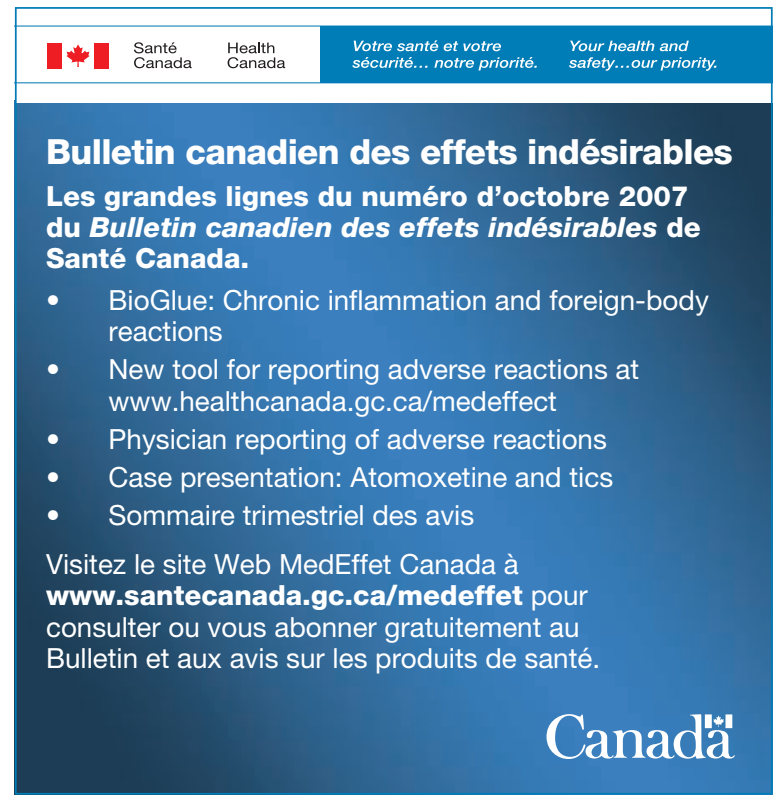

